\title{
Central Auditory Processing Disorder
}

National Cancer Institute

\section{Source}

National Cancer Institute. Central Auditory Processing Disorder. NCI Thesaurus. Code C97170.

A disorder characterized by impairment of the auditory processing, resulting in deficiencies in the recognition and interpretation of sounds by the brain. Causes include brain maturation delays and brain traumas or tumors. 